\title{
Hieroglyphic Semiotics of Emoji Signs in Digital Communication
}

\author{
Rusudan Makhachashvili ${ }^{1, *}$ Anna Bakhtina ${ }^{1}$ Svitlana Kovpik ${ }^{2}$ Ivan Semenist ${ }^{1}$ \\ ${ }^{I}$ Borys Grinchenko Kyiv University, Ukraine \\ ${ }^{2}$ Kryvyi Rih State Pedagogical University, Ukraine \\ *Corresponding author.Email: r.makhachashvili@kubg.edu.ua
}

\begin{abstract}
This paper is a parcel of a series of studies carried out by the group of authors on the structural and systemic specifics of the artificial language emoji. In this study, this problem is considered through the prism of two linguistic dimensions of existence - natural language (Chinese) and artificial (emoji). This approach is related to the semiotic nature of languages - hieroglyphics (Chinese), iconicity (emoji), the structure of which implies an aletic (from the Greek $\alpha \dot{\lambda} \eta \dot{\theta \varepsilon 1 \alpha}$ - truth) sign in terms of content and expression. Taking into account the specifics of the use of hieroglyphic and iconic writing in digital communication, an empirical experiment was conducted with the method of transformation of hieroglyphic and iconic signs, the denotation of which is the "sun". In addition, the formalization of the form of signs and comparative analysis of the elements of the whole sign with consistent approbation of their integral form and content proved that the occasional is a rectangular form of the Chinese character "sun", its perception - completely usual rays in the form of lines around it, where the geometric figure of the circle is qualia. The results of the experiment allowed to fractalize the scheme as a complex implicative statement, in which the deductivization of the sign explains its main stages (ontological denotation, conceptual denotation, lingual denotation), which provided for the formalization of the content plane in the digital transformation of the expression plane, approbation of the emoji sign via the Lexonomy digital lexicographic system. In view of all the above, the phenomenological specificity of natural languages, as well as ICT allowed us to determine the hieroglyphic and iconic signs of the logos. The sample of the generation of the emoji sign is disclosed, which is based on the signs of the alternative model of digital presentation of fiction created with the help of the Emoji-Maker platform and tested by linguists-in-training.
\end{abstract}

Keywords: emoji, hieroglyph, sign, polylaterality, computer being, qualia, structure, logos, system.

\section{INTRODUCTION}

Problem Statement. Natural languages are an inexhaustible substrate for the construction of artificial languages. First of all, the external elements of the sign are transgressed - its structure. The most striking example of such re- and construction of signs is the hieroglyphic and iconic writing, which in synthesis is the semiosis of the pictographic image. However, it is in optics that the problem of generating a sign, and hence its communicative function, lies, because the image appeals not only to the structure but also to the physical and emotional characteristics of the sign, an important example of which is the artificial language of digital communication - emoji.

\begin{abstract}
Computer being (CB) enables the multifunctionality and multimodality of the anthroposphere as a set of subjects of the CB, their activities, and socio-cultural heritage. Hieroglyphic and iconic writing occupies a special place in the digital space because their transgression requires a special codifier that will ensure the functioning of the specified algorithms. Hieroglyphic writing on an absolute level is subject to digital fractalization, thanks to the binary system based on Chinese writing in the XVIII century. G. Leibniz, which we will trace in our study. However, the problem is the digital fractalization of the emoji language, as the iconic letter is based on the personal Unicode identifier, which makes it impossible to identify characters with subsequent formal fractalization on different digital
\end{abstract}


systems. Therefore, the study design comprised of the following research tasks:

1. To conduct an empirical experiment with the method of transformation of hieroglyphic and iconic signs in order to synthesize the semantic load of signs in digital communication.

2. To fractalize the scheme obtained during the experiment as a complex implicative argument, in which the deductivization of the sign will allow the explication of its main tiers (ontological denotatum, conceptual denotatum, lingual denotatum).

3. To identify the substrate of sense explication and find ways to resolve it using lexicographic cloud technologies, i.e. to transgress the sign into denotata of different tiers of the microstructure of the ICT content plane, expanding the sign as a text (logos), which works in the multimodal dimension of natural language on the mental level.

4. To verify the multimodality of the logosphere of computer being, based on the example of the iconic sign as an alternative model of digital presentation of text, created using the Emoji-Maker platform.

The paper objective is to investigate the isomorphic structure of the generation and regeneration of a natural language sign and the sign of computer being with the help of logical-cognitive, structural-logical, and semiotic approaches. The validity of the inquiry is verified by the emoji corpus having been previously tested by linguists-in-training as an alternative model of digital presentation of fiction: the created images reproduce the multimodal concept of the metalinguistic field.

Related research. During the study, the logical and philosophical works and linguistic works of such scientists of the world as L. Wittgenstein [26], R. Carnap [15], R. Makhachashvili [6, 10, 11], K. Popper [27], B. Russell [28] became important and valid; works by prominent orientalists: V. Rezanenko [12], I. Semenist [24, 25], Y. Shcherbakov [29] In recent years, artificial languages, and in particular the language of emoji, have become the object of such scholars as A. Bakhtina [10, 11], M. Danezi [22], O. Piperski [23].

\section{RESEARCH METHODOLOGY}

The following methods were used to carry out the inquiry tasks: the structural-systemic method was applied to determine the following goals: to identify individual parts of the object and their features; on the basis of features of separate parts to deduce specificity of the whole object; to determine the phenomenon of integrity, having studied the patterns of connection of elements into the system, the structure of the object that forms the core of the system approach; to reveal the genesis of the system, its connections with other systems. The empirical method was applied during an experimental study on the generation and regeneration of hieroglyphic sign and emoji sign in digital communication; application of a systems approach in order to consider the object as a model of the system; functional approach - to determine the functions performed by the model; logical-semantic method, which is characterized by the use of data from different research fields, in particular at the intersection of linguistics, logic, digital humanities, philosophy, psychology, physics, which together appeals to the explication of individual features of a sign and its dependence on the objective properties of the real and digital continuum sign.

\section{FINDINGS AND DISCUSSION}

Sensory sensations are the foundation of physicalist perception and empirical comprehension of these sensations with the help of sensory-speech cortex (Wernicke zone) [1] and kinetic-motor verbal analyser of proprioceptive information processing (Brock zone) [2]. Synthesizing the process of their properties, both zones generate phonological and syntactic codification, the visualization of which will be individual. To study and conclude the latter, we use the term qualia, which was introduced into analytical philosophy to denote the most common thing for us: how things look to us. They can be defined as qualities or sensations, such as redness or pain, and are considered separately from their impact on behaviour, as well as from any physical conditions that may have caused them. In more precise philosophical terms, qualia is a property of sensory experience [2]. The functionality of qualia is explained by the example of a red apple, i.e. in this case qualia is redness, not the apple itself or its properties. We can note that extensionally "redness" is a signification of the denotatum "apple". Appealing to the theory of logical semantics of G. Frege [5] and explaining the correlation between the apple and its redness, we visualize an example based on the logical triangle of Frege (Fig. 1).

According to the above scheme, we observe a correlation between denotation, concept, and sign, which demonstrates the dependence of the sign on both objectively existing reality (denotation - red apple) and subjective perceptions of this reality (concept - redness). 
In turn, Lewis considered this term from the vision of the mental structure of human consciousness, and hence qualia as a property of mental states. "The way you feel it when you experience such mental states as pain when you see the color red, feel the scent of roses, etc." [4].
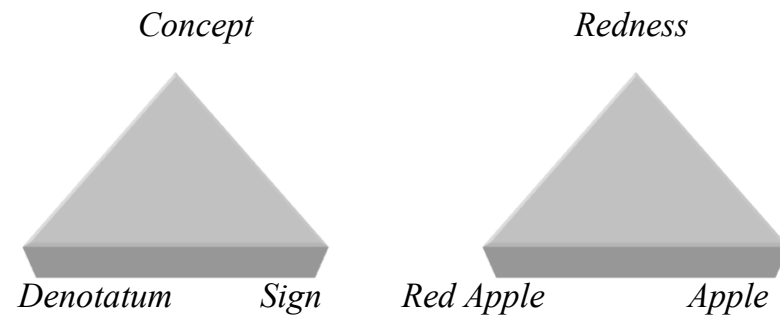

Figure 1 Logic triangle retransmission on the properties of qualia.

Given that mentality is a codifier of human consciousness, we ask ourselves the question: what is the mentality in the modern digital world, which, operating with traditional logical and linguistic properties, determines computer being (CB) - a complex, multidimensional sphere of synthesis of reality, human experience and activity, mediated by the latest digital and information technologies; the technogenic reality, a component of the technosphere of existence. A new sign in the computer being is a type of cybermorphism - the assimilation of an object and/or phenomenon of a non-computer environment to an element of computer being on the basis of substrate and substrate features (Makhachashvili R.) [6, 25]. Programming language nominates this mentality with the Unicode, a digital identification, but the strategy and technology of the process of transition of the mental code of traditional languages into the mental code of artificial languages of the CB are important to this inquiry.

The above question is explained by I. Zaitsev [7], so that during the signification and functionality of the mental code in the $\mathrm{CB}$ both zones of the cerebral cortex are synthesized, producing ratio and emotio with their digital transcoding into artificial languages. The explanation is confirmed by the example of the "Chinese body" (China-body system), which, according to the scientist, demonstrates qualia. Imagine that "every Chinese out of a billion Chinese is provided with a two-way walkie-talkie to communicate with other Chinese and an artificial body without a brain. The movements of the body are controlled by radio signals, and the signals themselves are sent according to the instructions that the Chinese people receive from the big screen in the sky. All Chinese see the screen. The instructions are given in such a way that the Chinese who operate on them function like individual neurons, and radio communication acts as synapses. That is, in general, the entire Chinese people duplicate the neuro-dynamic organization of the human brain. If such a system had ever been implemented, could it really experience feelings and sensations? Logically, this is impossible. But if there is a metaphysical possibility, then the qualifications do not have a functional essence. It is also stated that any system that is our complete functional duplicate will be subject to all the same beliefs, including thoughts about our inner states. Thus, the "Chinese body" system will be convinced that it feels pain, and if it has similar thoughts, it will be able to become the subject of some sensations (and, consequently, some phenomenal states)" [7]. And, therefore, the example of the "Chinese body" only confirms the existence of qualifications in the $\mathrm{CB}$, which functions as the basis of the mental code, transgressing the properties into an Artificial Intelligence system.

However, the example with the "Chinese body" is mentioned by us not only in the information plane of theoretical provability of the correlation of sign, denotation, and concept, which in computer being (CB) is converted into qualia. This example also explains the very nature of the origin of hieroglyphics with its subsequent transformation into a modern linguistic phenomenon of the innovative logosphere [6] - emoji - (from Japanese 絵 - picture and 文字 sign, symbol; Japanese pronunciation [emodzi]) special language ideograms, non-phonetic, multimodal written signs to express a wide range of human emotions in the texts of various digital media [11]. Since emoji, as an object of the linguistic structure of computer being, reproduces the global and transnational perception of the sign, preserving the mental factors of any nationality, we note the versatility or multi-vector nature of the content plane. R. Makhachashvili R. and A. Bakhtina nominate multi-vector as polylateral - "(from the ancient Greek $\pi \mathrm{o} \lambda \dot{v}$ - many; from Latin latus - side) - a category that reflects in the sign emoji versatile, multi-vector reproduction of emotions through logical-structural, lexical-grammatical, morphological and other means "[11]. Therefore, in view of the above, we consider it necessary to nominate the phenomenon of "emoji" logos emoji, which means the digital cache of linguistic cybermorphisms and extralinguistic factors projected in it, which includes the duality of knowledge and knowledge of the world - ratio and emotio, facilitating logical-emotional basis of human thinking by means of coding of computer being by algorithms of artificial intelligence. The emoji logos transgresses from a sign (emoji symbol) to a code 
(text) and vice versa. The latter will allow us to study digital language signs in synthesis with various natural and artificial empirical-essential data, given that such a digital model is nonlinear.

The synthesis of natural and artificial languages, ratio and emotio, transgresses the meaning of the code (message) into the semiotic-informational concept of language in its reproduction by the dichotomy "manmachine". G. Melnikov demonstrated the above concept with the help of a "communicative arc" [8], which is presented below (Fig. 2).

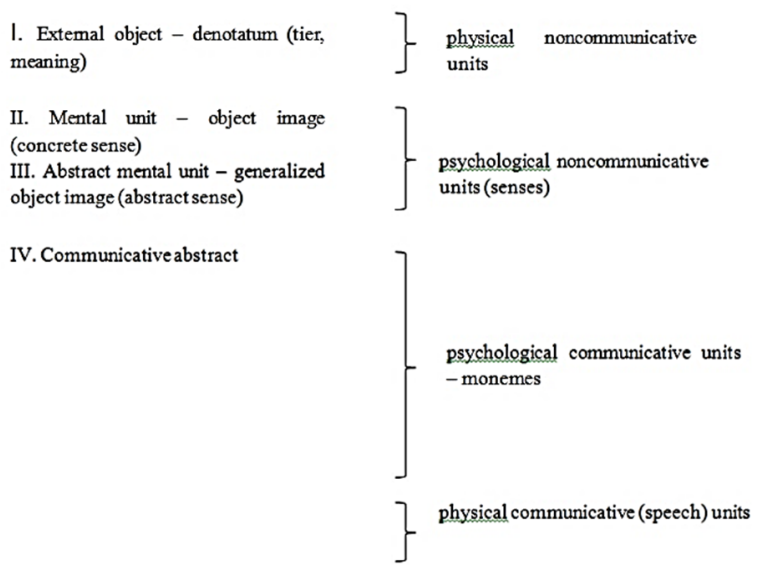

Figure 2 Communicative arc by G. Melnikov.

A sign situation (language - subject) determines the relationship between a sign and a denotation (abstract or physical object). However, communication can be considered accomplished only if the image of the sign and the image of the denotatum is generated in the sign situation, a clear example of which is G. Melnikov's "communicative arc". The scheme demonstrates a chain of successive transitions from the real denotation (I) and its reflection in the mind through the occasional meaning (II) to its usual meaning (III). The latter, due to direct association, forms a meaning (IV), combined in a moneme with a language sign $(\mathrm{V})$, which, in turn, initiates the reproduction of a speech sign (VI) [8]. All this points to the structural limitations of the "communicative arc" in the sign system of artificial language, the mechanisms of which are interconnected by one common sense.

In the semantization of the emoji logos in the dichotomy of "man-machine", by analogy with the "communicative arc", we take into account both the usual and occasional meanings. By the latter we mean, first of all, the mental characteristics of the visualization and systematization of the sign, which form a model for the appropriate expression of individual (mental) features. The latter refers us to the logical triangle Frege and Lewis's statement about mental characteristics: "How you feel it when you experience such mental states as pain, when you see red, feel the scent of roses, etc.". [4].

The hieroglyphic sign, or rather its semantization, is the most striking example of the synthesis of usual and occasional meanings in the human-machine dichotomy, where the sign is essentially an immanent image of the denotation (communicative arc: see above). Let's pay attention to Fig. 3 - the scheme of the hypothesis of mirror physicalistic reproduction of the form and content of the sign, where the hieroglyphic sign is taken as an example, which is an immanent example of the logical-cognitive whole of the sign, and the emoji sign is a pictographic image of the sun [11]:

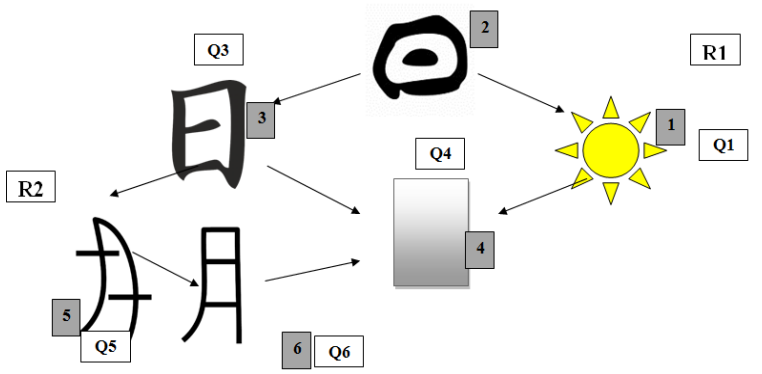

Figure 3 The hypothesis scheme of the mirror physicalistic reproduction of the form and content of the sign "the sun" [11].

Figure 3 depicts two similar in meaning iconographic signs meaning the concept of "sun". Hieroglyph 日 (rì - sun) and a pictographic image of the sun using emoji in digital communication. However, a retrospective feature of the concept of the "sun" reproduces its mirror image. From the very beginning, the concept of the sun was designated pictographically:

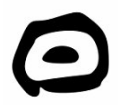

Figure 4 Ancient Egyptian "Sun” Icon.

This image in the form of a circle with a dot in the center is due to the belief of the ancient Chinese in cosmic energy, and it was believed that the sun is designed to observe everything that happens in the four corners of the world. However, the pictographic image underwent a process of simplification until it transgressed into the standard (mental) form for hieroglyphs - a square or other shape with angles. This simplification was due to the expansion of the lexical and semantic field of the Chinese language. It is easier 
to add another hieroglyph or its elements that generate a new word to an existing hieroglyph that has a rectangular shape. Such hieroglyphs are qualified as compounds (in the text they can often be used as independent radicals). By accepting the transformed (see Fig. 3) experiment of empirical observation we explain the iconographic image of the sun: the mechanisms of the iconic image of the sun are monolithic. This confirms our statement about the synthesis of usual and occasional meanings. Occasional (mental) in this case is the rectangular shape of the Chinese character "sun", its perception completely and utterly usual, reproduced by general standards - a yellow circle with rays in the form of lines around it, where the geometric figure of the circle is qualia (i.e. a circle). $\rightarrow$ the concept of the sun) (Fig. 5):

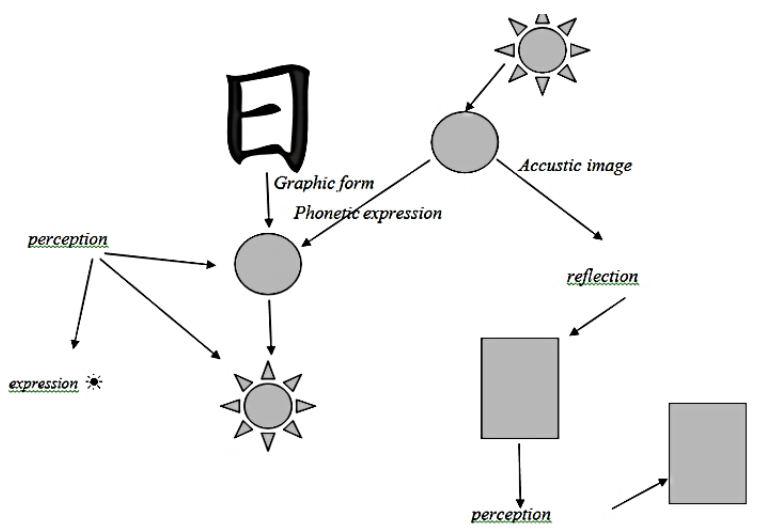

Figure 5 Structure qualia of the sign "sun".

A renowned orientalist $\mathrm{V}$. Rezanenko defined the semiotic and semantic basis of the hieroglyph as follows: "The Chinese hieroglyph is a symbol that embodies certain elements of national traditional culture. Sentences in the hieroglyphic text are not represented by token-parcels of the sentence or parts of speech, but by codes, i.e. hieroglyphic symbolscarriers of elements of traditional Chinese culture. The speech flow of the bearer of this culture consists of these symbols in their sound (phonetic) or graphic plans of expression. Thus, the mentioned language flow is a stream of consciousness, the basis of which is the worldview principles, which, as noted above, are formed and actualized in the syncretism of the three religious and philosophical teachings. The common ideological basis for the development of these teachings is the Taoist doctrine, the methodology of which is based on the idea of yin-yang cosmic rhythmic cycles as the main principle of the life of all things. The model of these rhythmic cycles in Taoism is the well-known circle of tai chi, which we call the Taoist circle. It is the semantics of the graphic structure of this circle that we have laid the foundation for the semantic-graphic structure of the ideograms of Chinese hieroglyphic writing" [12]. Thus, we conclude that the Chinese hieroglyph "sun", which has a square shape, symbolizes the sun's illumination of the entire Earth with four rising points (west, dawn, day, night / North-South, West-East).

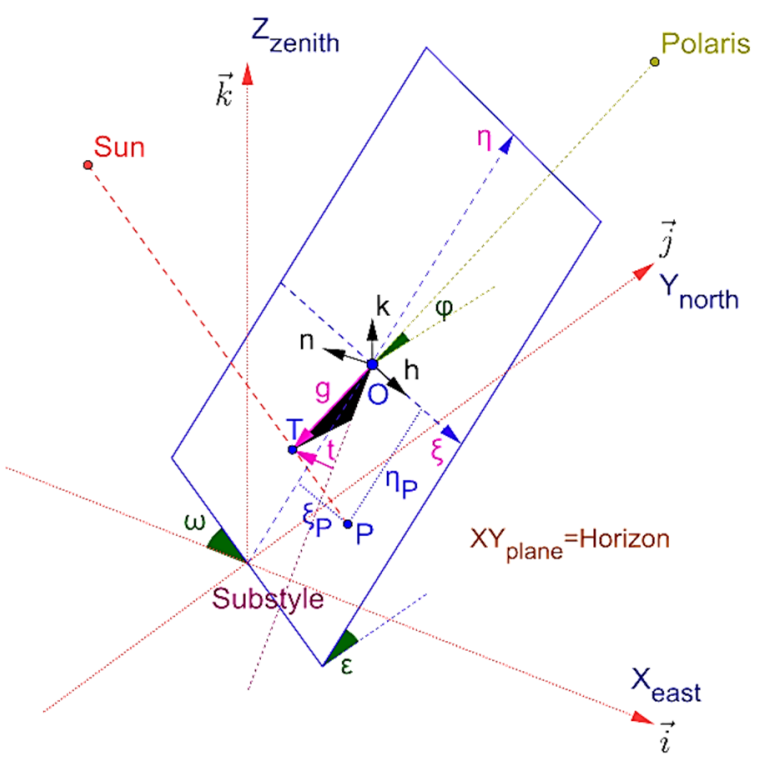

Figure 6 (a) Structural and functional significance of the gnomon.

In computer being, we observe the semanticization of the concept of "sun" with the help of qualification + pictographic generation of the sign, where perception, in turn, will be identical to the occasional hieroglyph "ri". And this perception is provided due to the signs of usuality in associativity - the square is a physicalist perception of proprioceptive information. By analogy: we cannot sensory feel the shape of the sun, but we can visually perceive the shape of its shadow on the earth, and this shadow has a rectangular shape. This is achieved with the help of an ancient astronomical instrument for measuring time - the gnomon (Fig. 6 $\mathrm{ab}$ ). The main element of the gnomon is a vertical pole that casts a shadow on a horizontal area. The tool allows you to determine the time by phases of the sun. Thus, according to the shape of the gnomon, the shadow from the sun mostly has a square, rectangular or triangular shape: "The rectangular figure in the diagram is key. In Chinese, it is a substrate figure in the generation of a hieroglyph; in general, under the condition of physical reproduction of an object, the shadow of the sun is formed by a rectangular shape. This is due to the ancient astronomical device gnomon. Its main structure is a vertical pillar, which, in fact, cast a shadow from the sun on the Earth's surface. Therefore, for different lengths and latitudes of rectangular shadow shapes, it was possible to 
determine the time. Consequently, in the physicalist perception, the qualia of the circle (sun) is a rectangular figure. Under all these conditions, a logical sequence of mirror reflection of the "sun" was generated [13].

Where the unitary modulus of the gnomon $(\mathrm{G}=1)$ becomes a simple scale of all measurements, depending on the displacement coordinate $(\xi, \eta)$ the projected shadows increase accordingly.

In the diagram we see two directions of gnomons: polar, to the Celestial North Pole, and perpendicular to the dial, provided that the cosines are equal to the normal vector $(\mathrm{gx}=\mathrm{a}, \mathrm{g} \mathrm{y}=\mathrm{b}, \mathrm{g} \mathrm{z}=\mathrm{c})$ [13]. Namely: $\vec{g}=g_{x} \vec{i}+g_{y} \vec{j}+g_{z} \vec{k} \quad$ (Polar gnomon) $\left\{\begin{array}{l}g_{x}=0 \\ g_{y}=-\cos \phi \quad \text { (being } \phi \text { the location latitude) } \\ g_{z}=-\sin \phi\end{array}\right.$

Figure 6 (b) Measurement scale for gnomon.

Thus, such a transgression of a sign in Computer Being can be considered mirroring: a circle $\leftrightarrow$ square, where the sign is an immanent image of a denotation (communicative arc: see above), and a circle is an image of a sign. Under such conditions, the communicative act in the $\mathrm{CB}$ is considered complete, because the pictographic and iconic image of the concept does not adiaphorize the usual meaning of the sun - the central body of the solar system, which synergistically reproduces the transitions of four rising points: dawn-sunset-day-night. Therefore, we can fractalize the above scheme as a complex implicative statement, in which the deductivization of the sign explains its main tiers (Fig. 7).

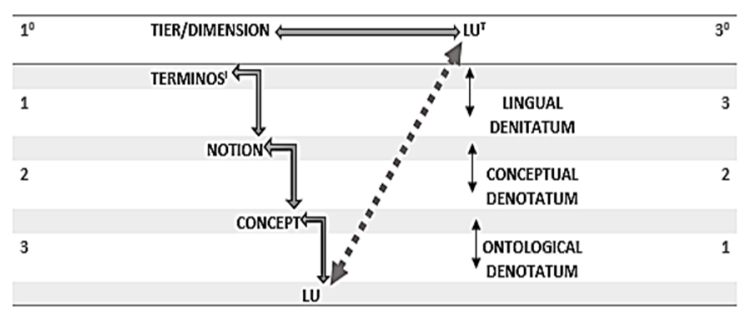

Figure 7 Tiered Microstructure of the Innovative Computer Term-logos.

Consequently, the level $\left(1^{0} / 1\right)$ - "ontological denotatum" - corresponds to parametric feature of "existential dimension" (substanteme), level (2) "conceptual denotatum" - to the parametric features of "concept" and level $\left(3^{0} / 3\right)$ "lingual denotatum" - to the parametric feature of "language units" (term/logos) [6].

According to the above scheme, we define the following: the ontological denotatum (logos) is the linguogenesis of the Sino-Tibetan language family, which in our case is visualized by the substance of the pictographic image of the sun, the existential dimension of which is parameterized not only in pictograms but also in the language (Chinese in particular). Thus, according to this, the conceptual denotatum (eidos) in view of the Chinese language is a rectangular shape, which, in fact, synthesizes the 2 nd and 3rd tiers in terms of hieroglyphic expression of content. In the universal dimension, the conceptual denotatum is the figure of a circle, which a-posteriori refers us to the logos. The lingual denotatum is a verbos "sun" / "ri".

It is necessary to trace the functionality of the polylaterality [11] of hieroglyphic and iconic signs at the structural level as well, which in particular will further explicate the main tiers of the sign (ontological, conceptual, linguistic denotata). Note, however, that in the case of the logographic (hieroglyphic) and iconic (emoji) writing, the verification of the functionality of the sign is deductive, namely from the highest (phenomenological) tier to the lowest (structural) as specific. This method is relevant to the specificity of a non-linguistic sign, the fractalization of which consists mainly of separating its elements into independent and amorphous parts or into surjective elements, in which at least one of the elements of the first sign is associated with each element of any other sign. However, the identification of a non-linguistic sign in a fractalized form is impossible: the sign becomes an active functional only if all the necessary elements are present in the synthesis. In fact, under the condition of surjection, non-linguistic signs are generated and transformed. Verification of the previous sentence is possible under the condition of digital adaptation of hieroglyphic and iconic signs. Let us trace the content plane in the digital transformation of the expression plane (hieroglyph) using a system of logs (via a corpus management and text mining tool - Sketch Engine):

lemma $="$ 的 "][word=" な "]?[tag="Pref"]? $1:[\operatorname{tag}=" N . * "$ \& tag!="N.num"] [20210106-14:18:04] $8 \%$ [20210106-14:18:04] warning: no results [20210106-14:18:04]

$2:[$ tag="Ana.*|N.c.ana"|tag="Ai.*"][lemma=" 樣 "][word=" な "][tag="Pref"]? 1:[tag="N.*" \& tag!="N.num"] [20210106-14:18:04] 9 \% [2021010614:18:04] warning: no results [20210106-14:18:04] >> 2:[tag="N.*" \& tag!="N.num"][tag="P.*"][tag="Ai.*" \& word!="な い|無い" \& infl_form="Attr.*"] [tag="Pref"]? $1:[\operatorname{tag}=" N . * " \quad \& \quad$ tag!="N.num"] [lemma=" 樣 "][infl_form="Concl.*"] [20210106-14:18:04] $18 \%$ [20210106-14:18:04] warning: no results [2021010614:18:04] $\gg>$ 2:[tag="N.*" \& tag!="N.num"] [tag="P.case" \& word=" が "] []\{0,2\} 
1:[tag="Ai. ${ }^{*} \mid$ Ana. $* \mid$ N.c.ana"][lemma="

"][infl_form="Concl.*"] [20210106-14:18:04] $18 \%$ [20210106-14:18:04] warning: no results [2021010614:18:04] >> 2:[tag="N.*" \& tag!="N.num"] [tag="P.bind" \& word=" は "] []\{0,2\} $1:[\operatorname{tag}=" A i$ * $\mid$ Ana.*|N.c.ana"][tag="P.*" \& word="で "] [tag="P.*" \& word=" の "] [tag="Pref"]? 1:[tag="N.*" \& tag!="N.num"] [20210106-14:18:04] $23 \%$ [20210106-14:18:04] warning: no results [20210106-14:18:04] >> 2:[tag="N.*" \& tag!="N.num"] [tag="P.*" \& word=" だけ "] [tag="P.*" \& word="の"] [tag="Pref"]? 1:[tag="N.*" \& tag!="N.num"] [20210106-14:18:04] $24 \quad \%$ [20210106-14:18:04][lemma=" 為 る "] [2021010614:18:04] $30 \%$ [20210106-14:18:04] warning: no results [20210106-14:18:04] >> 2:[tag="N.*" \& tag!="N.num"] [tag="P.case" \& word="で"] [] $\{0,5\}$ 1:[tag="V.*"] [20210106-14:18:04] $30 \%$ [2021010614:18:04] warning: no results [20210106-14:18:04] >> 2:[tag="N.*" \& tag!="N.num"] [tag="P.case" \& word="で"] []\{0,5\} 1:[tag="N.c.vs"] [lemma="方 "][tag="P.*"][tag="N.*" \& tag!="N.num"][word=" よ り "]1:[tag="Ai.*|Ana.*|N.c.ana"] [2021010614:18:04] $44 \%$ [20210106-14:18:04] warning: no results [20210106-14:18:04] $\gg>2:[\operatorname{tag}=" N . * " \&$ tag!="N.num"][word="

よ

り

"]1:[tag="Ai.*|Ana.*|N.c.ana"] [20210106-14:18:04] $44 \%$ [20210106-14:18:04] warning: no results [20210106-14:18:04]

$1:[\operatorname{tag}=" V . g \mid$ N.c.vs"][lemma="

為 る

"]?[tag="P.conj"\& word=" て "] 2:[tag="V.bnd"] [20210106-14:18:04] $45 \%$ [20210106-14:18:04] warning: no results [20210106-14:18:04] $\gg>$ 2:[tag="Adn"]1:[tag="N.*" \& tag!="N.num"] [20210106-14:18:04] $45 \quad \% \quad$ [20210106-14:18:04] warning: no results [20210106-14:18:04] $\gg>$ 3:[tag="N.*|Suff.*" \& tag!="N.num"] 2:[tag="Ai.*" \& word!="ない|無い" \& infl_form="Attr.*"] [tag="Pref"]? 1:[tag="N.*" \& tag!="N.num"] [20210106-14:18:04] $46 \%$ [20210106-14:18:04] warning: no results [20210106-14:18:04] $\gg>$ 2:[tag!="P.*|Aux $\mid$ V.bnd $\mid$ Sym.*|Supsym.*|N.num|Ws" ] 1: [tag="Ai.*" \& word!=" ない|無い"＆ infl_form="Attr.*"] [tag="Pref"]? 3:[tag="N.*" \& tag!="N.num"] within! [word="が|の" | tag="N.*"] $[\operatorname{tag}=" \mathrm{Ai}$ **" \& word!=" ない|無い" \& infl_form="Attr.*"] [tag="Pref"]? [tag="N.*" \& tag!="N.num"] [20210106-14:18:04] $46 \quad \%$ [20210106-14:18:04] warning: no results [2021010614:18:04] $>>$ 2:[tag!="P.*|Aux |V.bnd $\mid$ Sym.*|Supsym.*|N.num|Ws" ] [tag!="P.*|Aux|V.bnd|Sym. *|Supsym.*|N.num|Ws"]
1: [tag="Ai.*" \& word!=" ない|無い" \& infl_form="Attr.*"] [tag="Pref"]? 3:[tag="N.*" \& tag!="N.num"] within! [tag!="P.*|Aux $\mid$ V.bnd $\mid$ Sym. ${ }^{*} \mid$ Supsym. ${ }^{*} \mid$ N.num $\mid$ Ws"] [word="が|の" | tag="N.*"] [tag="Ai.*" \& word!=" ない|無い" \& infl_form="Attr.*"] [tag="Pref"]? [tag="N.*" \& tag!="N.num"] [20210106-14:18:04] 47 $\%$ [20210106-14:18:04] warning: no results [20210106-14:18:04] >>> 1: [tag="Ai.*" \& word!=" ない|無い" \& infl_form="Attr.*"] [tag="Pref"]? $3:[\operatorname{tag}=" \mathrm{~N} . * "$ \& tag!="N.num"]

It is observed that in the logs hieroglyphic writing is reproduced by the plane of content and the plane of expression on two levels: hieroglyphic writing (radicals) and non-hieroglyphic writing (kana), which refers to the full reflection of the multi-vector character of the hieroglyphic sign, thus synthesizing all steps and transgressing into the microstructure of the ICTs content plane. However, the preservation of the semantic field at the structural level is a priori impossible with the digital identification of a hieroglyphic sign for two reasons: 1) the specificity of the hieroglyphic sign provides an ideographic (conceptual) explication of the content plane, which is interpreted from a specific concept to an abstract image, and therefore the phenomenological level of visualization of the sign verifies its effectiveness; 2) kana as a syllabic graphic alphabet is absent in the Chinese writing system and is relevant only to the Japanese script as an ordered system of signs for writing out verbal texts. Thus, the irregular arrangement of the kana signs in the Sketch Engine log system indicates not a plane of content, but a plane of expression, which made it possible to identify the hieroglyph as a whole using the existing syllabic alphabet of the Japanese language, which adopted the Chinese script. It can be concluded that the system of $\operatorname{logs}$ visualizes the surjective identification of the hieroglyphic sign, where the elements of the signs of the syllabic alphabet are associatively prolonged by the specifics of the hieroglyphics. Thus, kana is a codifier of a given hieroglyph and parameterizes the identification only within the hieroglyphic sign, but only in terms of expression.

Instead, emoji in Sketch Engine logs do not reproduce their structure either in terms of content or in terms of expression, which appeals to the conclusion of a specific algorithm for generating emoji, where the mental codifier is Unicode, which is the substrate of sign iconicity. Actually, according to the possibilities of formal reproduction, we differentiate hieroglyphic and iconic signs. 
However, it is worth noting the synergy with another type of software - Lexonomy (within the lexicographic framework project Horizon 2020 ELEXIS: observer institution from Ukraine is Borys Grinchenko Kyiv University; the academic coordinator is Doctor of Philology, Associate Professor Rusudan Makhachashvili, the executor is graduate student Anna Bakhtina). Lexonomy is a cloud-based dictionary assembly system, as well as an online dictionary publishing system that is highly scalable for adapting large dictionary projects as well as small lexicographical works, such as editing and publishing domain glossaries or terminological resources on the Internet. Lexonomy is already integrated with Sketch Engine, and the project aims to further develop and expand this grafting. Sketch Engine corpus data can feed lexicographic data to Lexonomy to create automatically generated dictionary drafts, and Lexonomy annotation can help extract data from Sketch Engine corpora during the record editing process. Due to the interaction of the two systems, it was possible to recognize the emoji language at the structural level (Fig. 8):

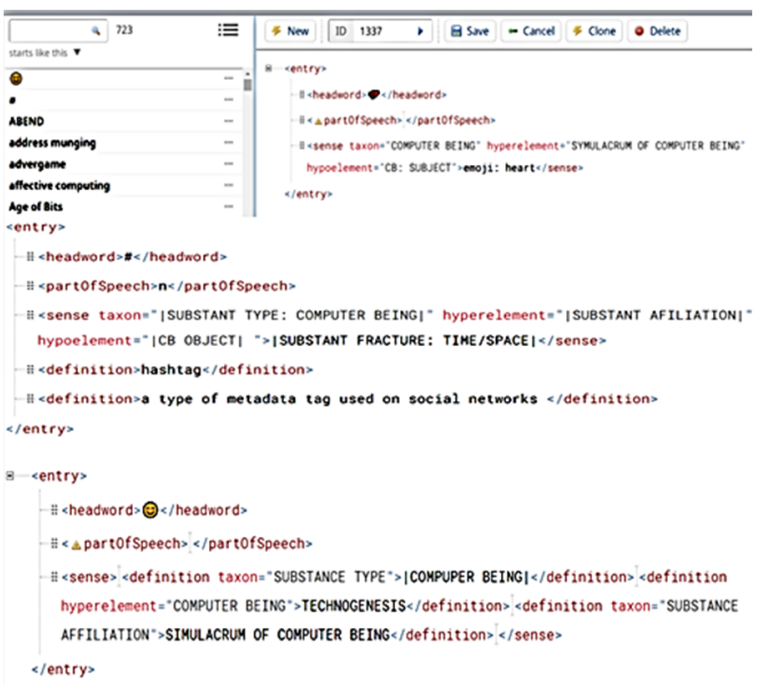

Figure 8 Corpus recognition the emoji language on the structural level.

We conclude that you can annotate the iconographic glossary to individual texts, upload data to the appropriate body, thus clarifying the operation of the program.

Given the substantive characteristics of innovative units of the logosphere of computer being, the phenomenological specificity of ICTs allows us to determine the correlative features of the logos as a single sign and the logos as an invariant and / or prescriptive text, more broadly - multimodal (multivector / polylateral).

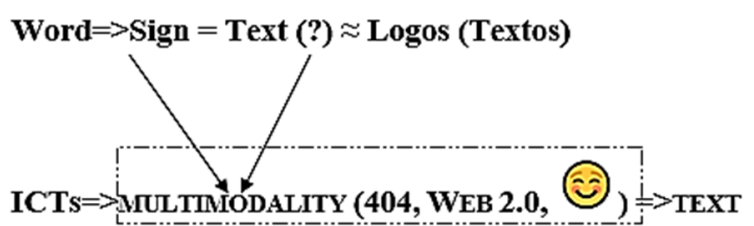

Figure 9 Multimodality of the logosphere of computer being.

Substantive characteristics of innovative units of the logosphere of computer being allow to determine the phenomenological nature of all tiers of the language system (including synsemantic), (Fig. 10):

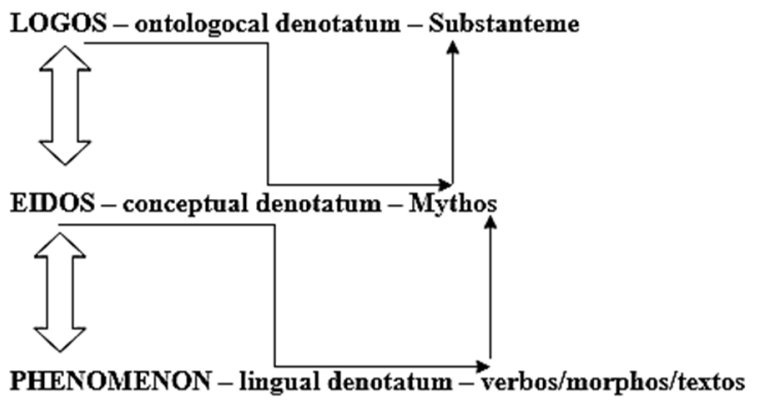

Figure 10 Phenomenological nature of the language system tiers.

The above is confirmed by the example of the generation of the emoji sign. We will take as a basis the signs of the alternative model of digital presentation of fiction created with the help of the Emoji-Maker platform and tested by studentslinguists: An attempt was made to compile the image of a lyrical hero on the Emoji-Maker platform (Fig. 11 ab). The created images, hieroglyphs of the XXI century, reproduce the multimodal concept of the metalinguistic field "[10].

According to the constructed emoji "Lyrical hero $=$ love + memory + imperishability" we determine the following steps.

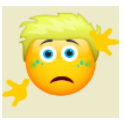

Figure 11 (a) Iconic Model of Fiction Presentation.

1. LOGOS - ontological denotation - noun (| e1... $\mathrm{n} \mid$ ) - computer being / social networks / Unicode Consortium as a resistant to the original (nonemotional connotation of emoji-sign) existential dimension, where the substrate is the emotional character of the sign.

2. EIDOS - conceptual denotation - myth $(x+y+$ $\mathrm{z}+\ldots \mathrm{n})-$ here we determine the characterized concepts of the generated sign, which, in fact, were chosen elements of semanticization of the emotional 
characteristics of the lyrical hero: love + memory + imperishability.

3. PHENOMENON - lingual denotation - verbos / morphos/text $(\mathrm{a}+\mathrm{b}+\mathrm{c}+\ldots \mathrm{n})-$ because the generated sign has a complex structure, in the digital continuum we can define only the immanent lingual denotation, for example, it can be "lyrical hero".

Take for example another emoji generated by poetry, which is in the position of "muse", which is addressed by the lyrical hero [10]:

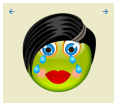

Figure 11 (b) Iconic Model of Fiction Presentation

1. LOGOS - ontological denotation - noun (|e1... $\mathrm{n} \mid$ ) - computer being / social networks / Unicode Consortium as a resistant to the original (nonemotional connotation of emoji-sign) existential dimension, where the substrate is the emotional character of the sign.

2. EIDOS - conceptual denotation - myth $(x+y+$ $\mathrm{z}+\ldots \mathrm{n})-$ appealing to the characteristics of the muse identified in the study, we distinguish the following concepts: love, sadness, grief, tears, longing. In addition, much emphasis is placed on choosing the color of the circle, indicating that green is the color of hope in love in Spanish culture. So, here we are dealing with a cognitive model using a mental frame green. Thus, the color of the generated sign is a discrete unit of collective consciousness, which reflects the object of the ideal world and is stored in the national memory of Spanish speakers in the form of a familiar verbally marked substrate.

3. PHENOMENON - lingual denotation - verbos / morphos/text $(\mathrm{a}+\mathrm{b}+\mathrm{c}+\ldots \mathrm{n})-$ as in the previous case, we casually create an immanent lingual denotation, for example, "muse", in the contextual space - text - taken as a basis a poem by H. Buesa, which was followed by a lingual-eidological transgression into LOGOS.

\section{CONCLUSIONS}

Thus, computer being enables the multifunctionality and multimodality of the anthroposphere as a set of subjects of computer being, their activities, and socio-cultural heritage.

The substrate for the accommodation of signs is hieroglyphic and iconic signs, which, in turn, are the semiosis of the pictographic image. However, we conclude that there is a differentiation in the algorithm for recognizing hieroglyphic and iconic characters in computer being. Hieroglyphic writing is subject to absolute transgression in the codification of the system of logs, thus fractalizing the plane of expression and the plane of content both at the level of hieroglyphics and at the level of non-hieroglyphic writing - kana.

Thanks to the cooperation of two cloud lexicographic systems - Sketch Engine and Lexonomy - the emoji language made it possible to fractalize the content plane and the expression plane. The problem of structural identification of emoji is the a priori language as artificial, and therefore one that has a personal identifier - Unicode, which, in fact, introduces the functionality of emoji on different operating systems.

In addition, emoji is reproduced/codified in the same way as hieroglyphics, provided that there is a key specific to the character: in the case of emoji, it is Unicode.

The synthesis of natural and artificial languages, the transgression of the elements of signs, transforms the meaning of the code (message) into a semioticinformational concept of language in its reproduction by the "human-machine" dichotomy. The approbation of the mentioned concept is a hieroglyphic-iconic experiment of semiosis of elements of signs, which confirms the synthesis of natural and artificial languages in computer being through the mediation of physicalistic qualification.

In order to trace the validity of our study, we managed to fractalize hieroglyphic and iconic signs as a complex implicative judgment, in which the deductivization of the sign visualizes its main stages, according to which explicated "ontological denotation", which corresponds to the parametric sign "existential dimension" signs "concept" and "concept", "lingual denotation" - a parametric sign "language unit" (term/logos).

\section{AUTHORS' CONTRIBUTIONS}

Rusudan Makhachashvili, Anna Bakhtina, Svetlana Kovpik and Ivan Semenist contributed to the design and implementation of the research, to the experimental computations, to the analysis of the results and to the writing of the manuscript.

\section{ACKNOWLEDGMENTS}

Empirical findings and survey procedures have been conducted under the auspices of Integrated Research framework of Romance Languages and Typology Chair of Borys Grinchenko Kyiv University European languages and literatures development in 
cross-communication context (0116 U 006607) and Integrated Research framework of Oriental Languages and Translation Chair of Borys Grinchenko Kyiv University Oriental Studies development in the framework of Higher Education Internationalization (0116U007073), and Integrated Research framework of the Chair of Ukrainian and World Literature (Kryvyi Rih State Pedagogical University, Kryvyi Rih) "Poetics of a literary text".

\section{REFERENCES}

[1] H. Goodglass, N. Geschwind, Language disorders, Academic Press, 1976.

[2] J.E. Azcoaga, Información semántica. Lenguaje interno. Pensamiento, Acta Psiquiátrica y Psicológica de América Latina 39 (1993) 107116.

[3] S.A. Kripke, Naming and necessity, in: Semantics of natural language, Springer, Dordrecht, 1972, pp. 253-355.

[4] C.I. Lewis, A survey of symbolic logic, University of California Press, 1918.

[5] J. Weiner, Frege explained: from arithmetic to analytic philosophy, vol. 2, Open Court Publishing, 2004.

[6] R. Makhachashvili, Dynamika anglomovnoyi innovaciynoyi logosphery komp'yuternogo buttya, Odessa, ONU, 2013.

[7] V.S. Ramachandran, E.M. Hubbard, Synaesthesia - a window into perception, thought and language, Journal of consciousness studies 8.12 (2001) 3-34.

[8] G.P., Melnikov, Language as a system and linguistic universals, in: Systematic research. Annual, 1973, pp. 183-204.

[9] B. Cassin, S. Rendall, C. Hubert, J. Mehlman, N. Stein, M. Syrotinski, E. Apter, J. Lezra, M. Wood (Eds.), Dictionary of untranslatables: A philosophical lexicon. Princeton University Press, 2014.

[10] R. Makhachashvili, S. Kovpik, A. Bakhtina, E. Shmeltser, Technology of presentation of literature on the Emoji Maker platform: pedagogical function of graphic mimesis, CEUR Workshop Proceedings 2643 (2020) 264-280.

[11] R. Makhachashvili, A. Bakhtina, Empirical method in the study of emoji polylaterality, International Humanitarian University Herald.
Philology 3(43) (2019) 141-144. DOI: https://doi.org/10.32841/2409-

1154.2019.43.3.34

[12] V.F. Rezanenko, Semantic structure of hieroglyphic writing. The basic structural elements, Kiev State University, 1985.

[13] R.R.J. Rohr, Sundials: History, theory, and practice, Courier Corporation, 2012.

[14] "EmojiTerra." • EmojiTerra $\bigcirc$ | Emoji Copy \& Paste | Get Emoji Meanings Online, https://emojiterra.com/.

[15] R. Carnap, Meaning and Necessity: A Study in Semantics and Modal Logic, 1959.

[16] A. Demchenko, Emoji language: :) or :(? Emoji Language: :) Or :(?, 2018. https://expert.ru/russian_reporter/2018/24/yazyi k-emodzi-ili/

[17] A. Robertson, W. Magdy, S. Goldwater, Emoji skin tone modifiers: Analyzing variation in usage on social media, ACM Transactions on Social Computing 3.2 (2020) pp. 1-25. DOI: https://doi.org/10.1145/3377479

[18] Emoji | Definition of Emoji by Oxford Dictionary on Lexico.com Also Meaning of Emoji, Lexico Dictionaries | English, https://www.lexico.com/definition/emoji

[19] V. Evans, We communicate with emojis because they can be better than words, Quartz, 2015. https://qz.com/556071/we-communicate-withemojis-because-they-can-be-better-than-words

[20] H. Miller, J. Thebault-Spieker, S. Chang, I. Johnson, L. Terveen, B. Hecht, Blissfully Happy" or 'Ready to Fight': Varying Interpretations of Emoji, in: Proceedings of the International AAAI Conference on Web and Social Media, vol. 10, no. 1, Mar. 2016. https://ojs.aaai.org/index.php/ICWSM/article/vie w/14757.

[21] H. Alshenqeeti, Are emojis creating a new or old visual language for new generations? A sociosemiotic study, Advances in Language and Literary Studies 7.6 (2016).

[22] M. Danesi, The semiotics of emoji: The rise of visual language in the age of the Internet, Bloomsbury Publishing, 2016. 
[23] A. Piperski, Construction of languages: From Esperanto to pre-Thracian. Alpina non-fiction, 2020.

[24] R. Makhachashvili, I. Semenist, A. Bakhtina, Digital skills development and ICT tools for final qualification assessment: survey study for students and staff of European and oriental philology programs, Open Educational eenvironment of Modern University (9) (2020) 54-68. DOI: https://doi.org/10.28925/24140325.2020.9.5.

[25] R.K. Makhachashvili, I. V. Semenist, ICT thesaurus modelling recommendations (based on innovations of European and Oriental languages), Studia Filologiczne 7 (2020) 117--128.

[26] R.M. White, Wittgenstein's Tractatus LogicoPhilosophicus': A Reader's Guide, A\&C Black, 2006.

[27] K. Popper, The logic of scientific discovery, Routledge, 2005.

[28] B. Russell, Introduction to mathematical philosophy. Courier Corporation, 1993.

[29] Ya.I. Shcherbakov, The life path and literary images of Confucius and his disciples in "Lunyu" (( 论 语, Confucius" Judgments and Conversations)): a literary-naratological aspect, Ukrainian Journal of Sinology Studies (2) (2020) $47-54$. 